Supplement of The Cryosphere, 13, 2407-2419, 2019

https://doi.org/10.5194/tc-13-2407-2019-supplement

(C) Author(s) 2019. This work is distributed under

the Creative Commons Attribution 4.0 License.

(c) (1)

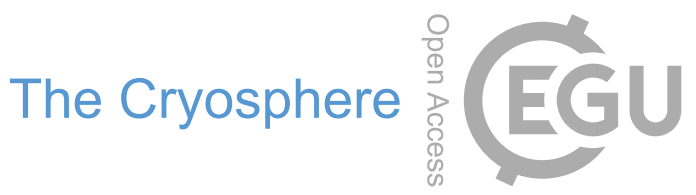

Supplement of

\title{
Very old firn air linked to strong density layering at Styx Glacier, coastal Victoria Land, East Antarctica
}

Youngjoon Jang et al.

Correspondence to: Jinho Ahn (jinhoahn@gmail.com)

The copyright of individual parts of the supplement might differ from the CC BY 4.0 License. 

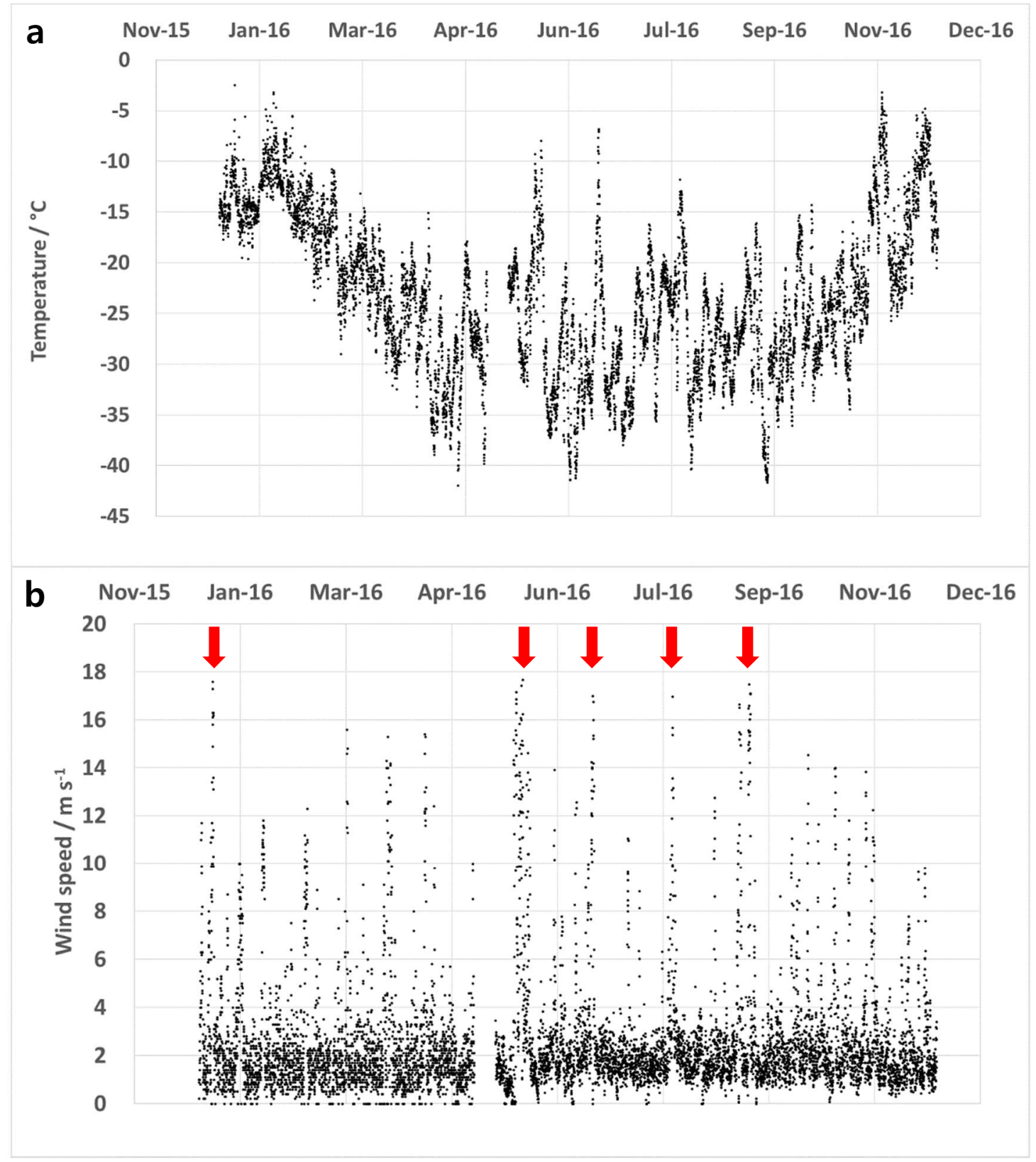

4 Figure S1. (a) Surface air temperature and (b) wind speed data from AWS (Automatic Weather System) 5 at Styx Glacier during December 2015 to December 2016. Red arrows indicate blizzard events. 